\title{
TTB2 induces apoptosis in Ewing sarcoma cells
}

\author{
XUELING ZOU and WENFENG HUANG \\ Hubei Key Laboratory of Natural Products Research and Development, Medical College, \\ China Three Gorges University, Yichang, Hubei 443002, P.R. China
}

Received May 11, 2016; Accepted April 21, 2017

DOI: $10.3892 /$ etm.2018.6236

\begin{abstract}
A steroidal saponin named pennogenin 3-O- $\alpha-$ L-rhamnopyranosyl- $(1 \rightarrow 2)$ [ $\alpha$-L-rhamnopyranosyl- $(1 \rightarrow 4)]$ $\beta$-D-glucoyranoside(TTB2) has been successfully separated from the $\mathrm{n}-\mathrm{BuOH}$ extracts of Trillium tschonoskii Maxim and is able to induce cytotoxicity to some types cancer cells. The present study aimed to investigate how this novel saponinin duces cytotoxicity in malignant sarcoma cells and to clarify its molecular mechanisms of action. It was determined this steroidal saponin induced the apoptosis in Rh1 cells and activated caspase-3 and caspase-9. Additionally, it disrupted the mitochondrial membrane potential and altered the expression of bax and bcl-2. Thus, the results of present study identified that an anticancer saponin isolated from Trillium tschonoskii Maxim may be developed as a potential novel therapeutic strategy to treat certain types of cancer, including lung cancer and lung sarcoma.
\end{abstract}

\section{Introduction}

Successful treatment with chemotherapeutic agents is largely dependent on their ability to trigger cell apoptosisin tumor cells (1). Many studies demonstrate that certain phytochemicals found in medicinal plants exert anti-tumor activity by inducing apoptosis in cancer cells $(2,3)$. Trillium tschonoskii Maxim, also named 'a pearl on head', mainly distributed in mid-western China, has been in folk used to cure headache, hypertension, neurasthenia, giddiness, cancer, eliminating carbuncles and relieving the pains for at least one thousand years (4,5). A Initial studies have demonstrated that variety of bioactive compounds including steroidal saponins and steroidal glycosides have been identified in plants belonging to the Trillium genus, such as Trillium erectum (6,7), Trillium kamtschaticum $(8,9)$ and Trillium tschonoskii Maxim (10). Active chemical components, including saponin polysaccharide, derived

Correspondence to: Professor Wenfeng Huang, Hubei Key Laboratory of Natural Products Research and Development, Medical College, China Three Gorges University, 8 Daxuelu Road, Yichang, Hubei 443002, P.R. China

E-mail: xyyxy1999@aliyun.com

Key words: steroidal saponin, anticancer, apoptosis from Trillium tschonoskii Maxim exhibit anti-bacterial and anti-cancer effects $(11,12)$. In a previous study $(12)$, it was also determined that pennogenin 3-O- $\alpha$-L-rhamnopyranosyl- $(1 \rightarrow 2)$ $[\alpha$-L-rhamnopyranosyl-( $1 \rightarrow 4)]-\beta$-D-glucopyranoside (TTB2) suppressed the proliferation of the Ewing sarcoma cell line and arrested cells in the G2/M and S phases of the cell cycle in a dose- and time-dependent fashion (12). Furthermore, the phosphorylation of extracellular signal-regulated kinase which serves an important role in tumorigenesis (12). However, it remains unclear which types of cancer cells TTB2 induces death induced by TTB2. In a previous study, it was demonstrated that TTB2, a steroidal saponin from the n-butanol extracts of Trillium tschonoskii Maxim, inhibits cell growth, induces apoptosis of Ewing sarcoma cells (12). Additionally, the present study indicated that TTB2 could trigger apoptosis protein cascades, decrease the mitochondrial membrane potential (MMP) and alter the expression of bax and bcl-2. The results suggest that TTB2 may execute its anticancer activity by inducing apoptosis and may be developed as a new class of chemotherapy drug.

\section{Materials and methods}

Reagents. Bovine serum albumin (BSA), the Annexin V-FITC Apoptosis Test kit and chloromethyl-X-rosamine (CMX-Ros) were all obtained from Sigma-Aldrich (Merck KGaA, Darmstadt, Germany). RPMI 1640 culture media and fetal bovine serum were purchased from Gibco, Thermo Fisher Scientific, Inc. (Waltham, MA, USA). BCA protein assay kit and ECL chemiluminescence system were supplied by PIERCE Biotechnology Inc. (Rockford, IL, USA). Rabbit polyclonal anti-caspase 3 and 9 (cat. nos. 9661 and 7237, respectively) were purchased from Cell Signaling, Inc. (Danvers, MA, USA). Mouse monoclonal anti-cytochrome c (cat. no. sc-65396), bax (cat. no. sc-7480), bcl-2 (cat. no. sc-7382), and tubulin (cat. no. sc-8035) were from Santa Cruz Biotechnology, Inc. (Dallas, TX, USA). Goat anti-Rabbit IgG secondary antibody (cat. no. A32731) and Goat anti-Mouse IgG secondary antibody (cat. no. A32723) were from Invitrogen (Thermo Fisher Scientific, Inc., Waltham, MA, USA). Other chemicals used in the current study were special grade commercial products.

Plant material, extraction and isolation of TTB2. The rhizomes $(6.4 \mathrm{~kg})$ of Trillium tschonoskii Maxim were picked from Muyu, a town in the Shennongjia Forest District of Hubei Province, China. The compound TTB2 
was extracted and isolated from Trillium tschonoskii Maxim following a previously published method (12). The TTB22 $\mathrm{mg}$ ) powder was dissolved in deionized water $60 \mu \mathrm{l})$. To prevent cell contamination, the TTB2 stock solution was filtered with 0.22 um-sized filtering membrane and separated into individual aliquots, which were kept at $-20^{\circ} \mathrm{C}$ until further use.

Cell culture. Rh1 cells, derived from mesenchymal tissue, are a type of human rhabdomyosarcoma cell, and were provided by St. Jude Children's Research Hospital, Memphis, TN, USA were cultured in antibiotic-free RPMI-1640 medium containing $10 \% \mathrm{FBS}$ at $37^{\circ} \mathrm{C}$ and $5 \% \mathrm{CO}_{2}$ for $24 \mathrm{~h}$ as demonstrated in a previous study (12).

Annexin V-FITC/PI cytometric analysis. To determine the mechanism by which TTB2-induced death of Rh1 cells, Annexin V and PI double staining were analyzed by Flow Cytometry (FCM, BD Biosciences, Franklin Lakes, NJ, USA). Rh1 cells $\left(2 \times 10^{5}\right)$ were seeded and incubated for $24 \mathrm{~h}$ at $37^{\circ} \mathrm{C}$. RPMI medium was replaced with an equal volume of fresh medium containing different concentrations (5 and $10 \mu \mathrm{M})$ of TTB2. PBS was used as the negative control. Following supplementation with TTB2 for $24 \mathrm{~h}$ all the cells containing attached and nonattached cell were collected and washed twice with PBS. Subsequently, the harvested cells were added to $400 \mu \mathrm{l} 1 \mathrm{x}$ binding buffer (obtained from the Annexin V/PI staining kit), $5 \mu \mathrm{l}$ Annexin $\mathrm{V}$ and $10 \mu \mathrm{l}$ PI staining, and kept in the dark for $15 \mathrm{~min}$. Apoptotic, necrotic and mechanically damaged cells were determined using flow cytometry software (BD FACSuite ${ }^{\mathrm{TM}}$; v1.0.5; BD Biosciences) with the single beam at a $488 \mathrm{~nm}$ wave length.

Assessment of mitochondrial membrane potential. CMX-Ros (cat. no. 40741ES50; Shanghai yisheng Biotechnology Co., Ltd., Qingdao, China) was used to analyze MMP. Rh1 cells $\left(2 \times 10^{5}\right)$ for each sample were seeded and incubated for $24 \mathrm{~h}$ at $37^{\circ} \mathrm{C}$. RPMI medium was replaced with an equal volume of fresh medium containing different concentrations of TTB2 (5 and $10 \mu \mathrm{M}$ ). PBS was used as the negative control. Following supplementation with TTB2 for $24 \mathrm{~h}$, all living cells were harvested and washed twice with PBS. MitoTracker Red CMXRos powder (50 $\mu \mathrm{g}$; cat. no. 40741ES50; Shanghai Yisheng Biotechnology Co., Ltd.) was dissolved in $94 \mu \mathrm{l}$ of dimethylsulfoxide to be used as a storage solution (1 mM Mitotracker Red CMXRos), which was stored at $-20^{\circ} \mathrm{C}$. Storage solution $(1 \mu \mathrm{l})$ was eventually diluted in $2 \mathrm{ml}$ PBS, which became the working solution with a final concentration of $500 \mathrm{nM}$ CMX-Ros. Cells were resuspended in $100 \mu 1$ of PBS containing $500 \mathrm{nM}$ MitoTrackerCMX-Ros and incubated for $45 \mathrm{~min}$ at $37^{\circ} \mathrm{C}$. Cells were washed with PBS and resuspended in PBS supplemented with $0.2 \% \mathrm{BSA}$ and then placed on ice prior to flow cytometric (FACSVerse; BD Biosciences, Franklin Lakes, NJ, USA) analysis with a single excitation beam at $488 \mathrm{~nm}$. MitoTracker Red CMXRos, an oxidized red fluorescent dye, travel across the cell membrane and gather in active mitochondria. Thus, once the mitochondria were stained, the probe remained within the cell. The stained cell was then directly analyzed using flow cytometry. Results were analyzed using BD FACSuite ${ }^{\mathrm{TM}}$ software v1.0.5 (cat. no. 657658; BD Biosciences).
Western blot analysis. Analysis of relative protein expression analysis was conducted by western blot method. Briefly, Rh1 cells $\left(2 \times 10^{5}\right.$ per well) were seeded in 6 -well plates and cultured until an $80 \%$ confluence was reached. Cells were then treated with indicated concentrations $(0,5 \mu \mathrm{M})$ of TTB2 for $24 \mathrm{~h}$ at $37^{\circ} \mathrm{C}$ and then harvested and washed with cold PBS. Cell pellets were lysed in $40 \mu \mathrm{l}$ lysis buffer (20 mM HEPES/NaOH, pH 7.5, $250 \mathrm{mM}$ sucrose, $10 \mathrm{mM} \mathrm{KCl}, 2 \mathrm{mM} \mathrm{MgCl}{ }_{2}, 1 \mathrm{mM}$ EDTA, $1 \mathrm{mM}$ DTT, protease inhibitor cocktail (cat. no. S8820-2TAB; Sigma-Aldrich; Merck KGaA) for 20 min on ice. The lysis solution was centrifuged at $25,000 \times \mathrm{g}$ for $10 \mathrm{~min}$ at $4^{\circ} \mathrm{C}$ and protein contents in the supernatant were measured using a DC protein assay kit (cat. no. 500-0119; Bio-Rad, Laboratories, Inc., Hercules, CA, USA). Proteins $(25 \mu \mathrm{g})$ were separated using $12 \%$ SDS-PAGE and transferred to polyvinylidene difluoride membranes. Membranes were then blocked with 5\% skimmed milk dissolved in Tris-buffered saline (TBS; $2 \mathrm{mM}$ Tris-HCl, $140 \mathrm{mM} \mathrm{NaCl}$; pH 7.6) with Tween-20 for $2 \mathrm{~h}$ at room temperature. Following five washes (each, $5 \mathrm{~min}$ ), membranes were incubated with corresponding antibodies against cytochrome $c$ (cat. no. sc-65396), bax (cat. no. sc-7480), bcl-2 (cat. no. sc-7382), caspase-3 (cat. no. 9661), caspase 9 (cat. no. 7237) and tubulin (cat. no. sc-8035; each 1:200) at $4^{\circ} \mathrm{C}$ overnight. Following five washes with TBS with Tween-20, membranes were incubated with corresponding horseradish peroxidase-conjugated secondary antibodies obtained from Santa Cruz Biotechnology, Inc. $(1: 5,000)$ for $50 \mathrm{~min}$ at room temperature. The bands were visualized using the ECL chemiluminescence system (Bioshine ChemiQ 4800 mini; Hangzhou Yaxu Biotechnology Co., Ltd., Shanghai of China) and subjected to densitometric analysis using Image-J2 software (National Institutes of Health, Bethesda, MD, USA) to semi-quantify the protein expression of TTB2 treated groups against the control group (tubulin).

Statistical analysis. All data were presented as mean \pm standard deviation. Data were processed with the SPSS 19.0 for Windows software package (IBM Corp., Armonk, NY, USA). One-way analysis of variance was used for statistical evaluations. Multiple comparisons between the groups were performed using Newman-Keuls test. $\mathrm{P}<0.05$ was considered to indicate a significant difference.

\section{Results}

Chemical structure of TTB2. The structure of TTB2is presented in Fig. 1. Its full chemical name is pennogenin 3-O- $\alpha$-L-rhamnopyranosyl- $(1 \rightarrow 2)$ [ $\alpha$-L-rhamnopyranosyl$(1 \rightarrow 4)]-\beta$-D-glucopyranoside.

TTB2 induces apoptosis in Rhl cells. To identify the nature of cell death, the early marker of apoptosis Annexin V and the dead cell marker propidium iodide were used to evaluate the cytotoxic effects of TTB2 on Rh1 cells. As presented in Fig. 2, following treatment with different concentrations of TTB2, the numbers of early apoptotic and late apoptotic/necrotic cells were determined. Treatment with 5 and $10 \mu \mathrm{M}$ TTB2 for $24 \mathrm{~h}$ resulted in 45.48 and $82.65 \%$ of Rh1 cells undergoing early apoptosis, respectively compared with $2.44 \%$ of cells in the control (Fig. 2A-C). These results indicate that the antitumor 


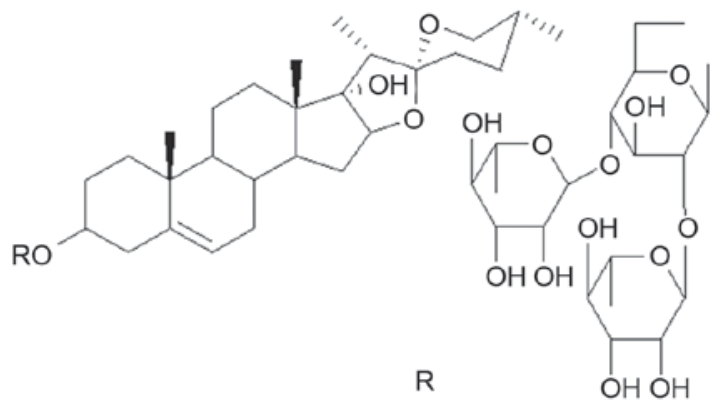

Figure 1. Chemical structure of TTB2. TTB2 is pennogenin 3-O- $\alpha-$ L-rhamnopyranosyl- $(1 \rightarrow 2)[\alpha-L$-rhamnopyranosyl- $(1 \rightarrow 4)]-\beta$-D-glucopyran oside (Molecular Weight: 884.48).

action of TTB2 is associated with the induction of potent apoptosis in a dose-dependent manner (Fig. 2D).

TTB2 treatment affects mitochondrial function. To determine whether changes in the MMP were implicated in the apoptosis induced by TTB2, cells were stained with CMX-Ros and analyzed using flow cytometry. Fig. 3 demonstrates that, compared with the control, treatment with 5 and $10 \mu \mathrm{M}$ TTB2 significantly decreased the MMP in Rh1 cells $(\mathrm{P}<0.05$; Fig. 3A). Additionally, the release of cytochrome $c$ following TTB2 treatment was evaluated using western blotting. The results demonstrated that there was a significant increase in cytochrome $c$ levels following treatment with $5 \mu \mathrm{M}$ TTB2 ( $<<0.05$; Fig. 3B and D). To determine the molecular mechanisms of apoptosis induced by TTB2, the levels of the anti-apoptotic protein bcl-2 and the pro-apoptotic protein bax were measured. Levels of bax significantly increased and levels of bcl-2 significantly decreased following treatment with TTB2 (both $\mathrm{P}<0.05$; Fig. 3D). These results indicate that TTB2 induces apoptosis in Rh1 cells via the intrinsic mitochondrial pathway.

TTB2 treatment affects the levels of apoptosis proteins. Western blotting was used to determine whether TTB2 treatment altered the levels of the cleaved apoptotic proteins caspases -3 and -9 . As presented in Fig. 3C and D, it was determined that TTB2 treatment activated caspases-3 and -9 . Compared with controls, TTB2 treatment significantly increased levels of cleaved caspases-3 and -9 (P<0.05; Fig. 3D).

\section{Discussion}

Cancer is a type of disease with poor patient prognosis. The incidence of most types of cancer continues to increase annually and the mortality rates generally remain high (13). Most tumors develop drug resistant following exposure to drug over a prolonged period of time $(14,15)$. Thus, it's imperative to develop novel medicines to reduce the morbidity and mortality of cancer. Steroidal saponins have been isolated from many types of medicinal plants. They have numerous pharmacological functions and exhibit biological activities, including cytotoxic, antifungal, enzyme-inhibitory, anti-inflammatory and antithrombotic activity (16-18). Compound TTB2, pennogenin 3 -O- $\alpha$-L-rhamnopyranosyl- $(1 \rightarrow 2)$ [ $\alpha$-L-rhamnopyra nosyl-(1 $\rightarrow 4)]-\beta$-D-glucopyranoside, is a steroidal saponin extracted from Trillium kamtschaticum (9) and Paris polyphylla var. Yunnanensis (19). However, there have been few studies investigating its bioactivity (9). It has been demonstrated that some pennogenin steroid analogues from other plants exerted different bioactivity (19). For example, pennogenin 3-O- $\alpha$-L-rhamnopyranosyl- $(1 \rightarrow 2)$ $[\alpha$-L-arabinofuranosyl- $(1 \rightarrow 4)]-\beta$-D-glucopyranoside from Paris polyphylla var. yunnanensis protects the stomach from damage induced by ethanol and indomethacin (20). Furthermore, certain analogues including pennogenin 3-O-alpha-1-rhamnopyranosyl-(1->2)-[alpha-1-rhamnopyranosyl(1->3)]-[6-O-acetyl]-beta-d-glucopyranoside from Dracaena (21), pennogenin 3-O-R-L-rhamnopyranosyl$(1 \rightarrow 2)$-[R-L-rhamnopyranosyl- $(1 \rightarrow 3)]-\beta$-D-glucopyranoside from D. deisteliana (20) and pennogenin $3-\mathrm{O}-\alpha-\mathrm{L}-$ rhamnopyranosyl-( $1 \rightarrow 2)-\beta-D$-glucopyranoside from Paris vietnamensis (22) were induce cytotoxicityin cancer cells. And we ever reported that TTB2 from the rhizomes of Trillium tschonoskii Maxim has the cytotoxicity on the Ewing sarcoma cell line and attenuate the cells in the G2/M and $\mathrm{S}$ phases (12).

When cells undergo apoptosis, phosphatidyl serine shifts from the inner side of the plasma membrane to its outer leaflet (23). Under this circumstance phosphatidyl serine is able to bind to Annexin V (24) and this property means that it is relatively easy to investigate apoptosis in all cells. The current study demonstrated the TTB2 potently induced apoptosis in Rh1 cells in a dose-dependent manner. Indeed, to the best of our knowledge, the current study is the first indicate that TTB2, a pennogenin steroid isolated from Trillium tschonoskii Maxim, could induce cancer cell line apoptosis. Mitochondrial dysfunction may trigger intrinsic pathway of apoptosis and is associated with numerous cell processes $(25,26)$. It has been reported that some stimuli such as radiation and toxins may stimulate the opening of mitochondrial permeability transition pores which then increase the permeability of the mitochondrial inner membrane, leading to disruption of ionic homeostasis, the collapse of MMP and cytochrome $c$ release (27). Furthermore, procaspase- 9 and released cytochrome $c$ may stimulate production of the apoptosome that drives the activation of caspase- 3 and eventually leads to the apoptosis (28). When cells are exposed to pathogens or mild inflammatory factors, the pro-apoptotic member bax shifts from the cytosol to mitochondrial outer membrane, which breaks the mitochondrial stability and facilitates the mitochondrial permeability transition and release of cytochrome $c$ (29). And anti-apoptotic protein bcl-2 is primarily located on mitochondrial outer membranes where it takes part in blocking membrane permeabilization (30). The results of the current study indicate that these molecular mechanisms involved in TTB2-treated Rh1 cells. Western blot analysis demonstrated that treatment with TTB2 provoked a marked decrease in the expression of bcl-2 and an increase in bax expression in TTB2-treated cells. Additionally, it was determined that TTB2 elevated the level of cytosolic cytochrome $c$, which serves a critical role in the formation of apoptosome as well as the caspase activation cascades that ultimately activates caspase- 3 . Combined with the results of previous study, which indicated that the TTB2inhibits the phosphorylation of extracellular 
A

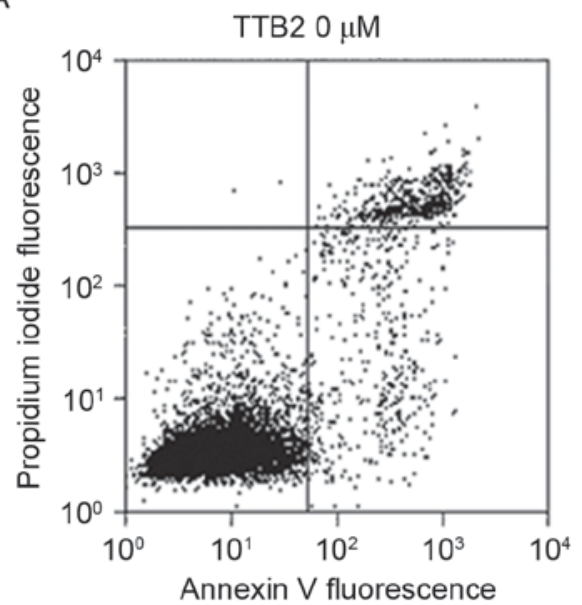

C

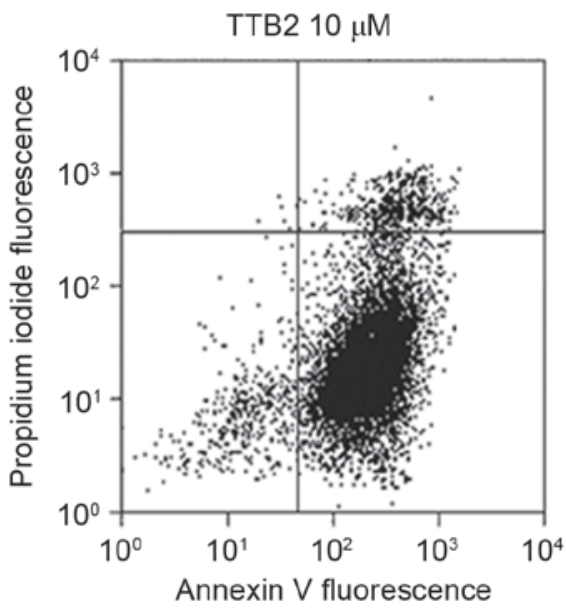

B

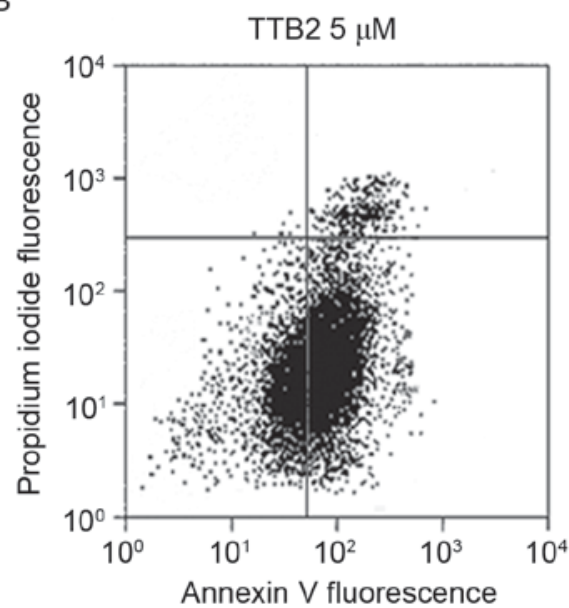

D

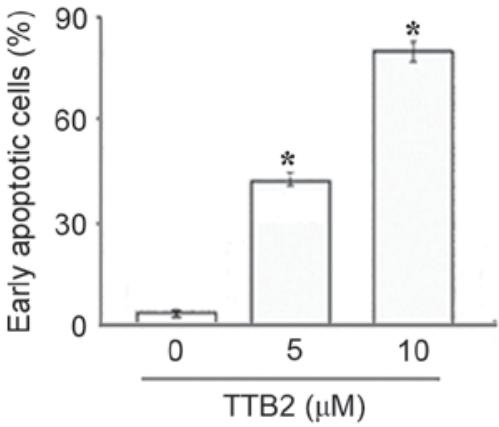

Figure 2. TTB2 induced Rh1 cells apoptosis by FCM. Results from flow cytometry indicating that TTB2 induced Rh1 cell apoptosis. The proportion of apoptotic and necrotic cells following treatment with (A) 0 , (B) 5 and (C) $10 \mu \mathrm{M}$ TTB2. The number of early apoptotic and late apoptotic/necrotic cells are presented in the lower right part and in the upper right parts of the graphs, respectively. (D) The total percentage of early apoptotic cells after $5 \mu \mathrm{M}$ or $10 \mu \mathrm{M}$ TTB2 treatment was dose-dependent. Analyses of cell distribution were performed by Annexin V-Propidium iodide double stainings. Presented results were from one of four independent experiments and data in graphs are presented as the mean \pm standard deviation. " $\mathrm{P}<0.05$ vs. control.

A

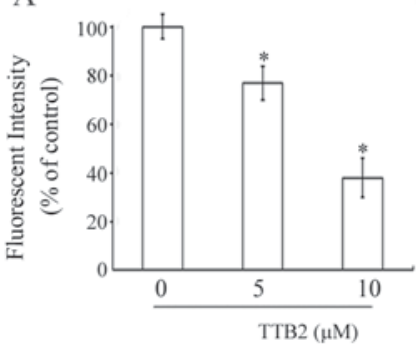

B

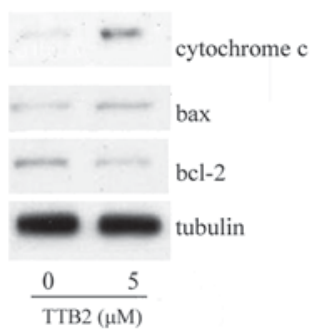

$\mathrm{C}$

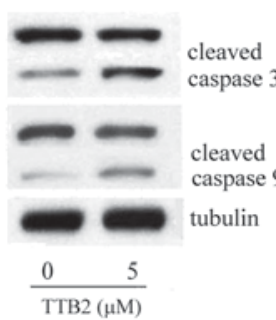

D

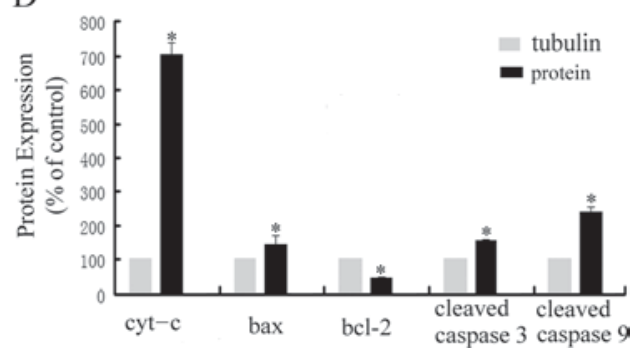

Figure 3. ТTB2 affected mitochondrial function and levels of apoptosis-related proteins. (A) Effects of TTB2 on mitochondrial membrane potential in Rh1 cells were detected by staining with CMX-Ros. Rh1 cells were treated for $24 \mathrm{~h}$ with the $5 \mu \mathrm{M}$ or $10 \mu \mathrm{M}$ TTB2 in triplicate. Data are presented as the relative difference compared with control and as the mean \pm standard deviation. ${ }^{*} \mathrm{P}<0.05$ vs. control. (B) Western blot analysis demonstrated that TTB2 treatment resulted in the release of cytochrome $c$ into cytosol. TTB2 also induced upregulation of bax and downregulation of bcl-2 expression. Tubulin was used as an internal control. (C) Western blot analysis was used to determine the changes in apoptotic protein expression following incubation of cells with $5 \mu \mathrm{M}$ TTB2 for $24 \mathrm{~h}$. TTB2 treatment markedly increased cleavage of caspase-3 and -9. All the experiments were performed at least three times. (D) Densitometric analysis of western blots. Data are presented as the relative optical density difference compared with control. Data in graphs are presented as the mean \pm standard deviation. ${ }^{*} \mathrm{P}<0.05$ vs. control.

signal-regulated kinase and promotes cell cycle arrest (12), the present study determined the procedures that have been closely implicated in the apoptosis of Rh1 cells caused by TTB2.
In conclusion, the results of the current study identified that the effects of TTB2 on Rh1 cells rely onTTB2-induced apoptosis, which is closely associated with mitochondrial signaling pathways. The current study suggested that TTB2 
isolated from Trillium tschonoskii Maxim may be developed as novel anti-cancer drugs in the future.

\section{Acknowledgements}

Not applicable.

\section{Funding}

This study was financially supported by the National Natural Science Foundation of China (grant nos. 31070313 and 21272136), Hubei Province Natural Science Foundation (grant no. 2016CFB444) and Yichang Science and Technology Research and Development Project (grant no. A201230234) and CTGU Talent Scientific Research Initial Foundation (grant no. KJ2012B063).

\section{Availability of data and materials}

The datasets used and/or analyzed during the current study are available from the corresponding author on reasonable request.

\section{Authors' contributions}

$\mathrm{XZ}$ and $\mathrm{WH}$ designed and completed the experiments, and analyzed the results together. WH was a major contributor in writing the manuscript. Both authors read and approved the final manuscript.

\section{Ethics approval and consent to participate}

Not applicable.

\section{Consent for publication}

Not applicable.

\section{Competing interests}

The authors declare that they have no competing interests.

\section{References}

1. Pistritto G, Trisciuoqlio, Ceci C, Garufi A and D'Orazi G: Apoptosis as anticancer mechanism: Function and dysfunction of its modulators and targeted therapeutic strategies. Age (Albany NY) 8: 603-619, 2016.

2. Millimouno FM, Dong J, Yang L, Li J and Li X: Targeting apotosis pathway in cancer and perspectives with natural compounds from mother nature. Cancer Prev Res (Phila) 7 : 1081-1107, 2014

3. Yang LJ and Chen Y: New targets for the antitumor activity of gambogic acid in hematologic malignancies. Acta Pharmacol Sin 34: 191-198, 2012.

4. Fu L (ed): Plant Red Book of China: Rare threatened plant. Science Publishing House Press, Beijing, 1992.

5. Li Q, Xiao M, Guo L, Wang L, Tang L, Xu Y, Yan F and Chen F: Genetic diversity and genetic structure of an endangered species, Trillium tschonoskii. Biochem Genet 43: 445-458, 2005.

6. Hayes PY, Lehmann R, Penman K, Kitching W and De Voss JJ: Steroidal saponins from the roots of Trillium erectum (Beth root). Phytochemistry 70: 105-113, 2009.

7. Yokosuka A and Mimaki Y: Steroidal glycosides from the underground parts of Trillium erectum and their cytotoxic activity. Phytochemistry 69: 2724-2730, 2008.
8. Ono M, Sugita F, Shigematsu S, Takamura C, Yoshimitsu H, Miyashita H, Ikeda T and Nohara T: Three new steroid glycosides from the underground parts of Trillium kamtschaticum. Chem Pharm Bull (Tokyo) 55: 1093-1096, 2007.

9. Nohara T, Miyahara K and Kawasaki T: Steroid saponins and sapogenins of underground parts of Trillium kamtschaticum Pall. II. Pennogenin- and Kryptogenin 3-O-Glycosides and related compounds. Chem Pharm Bull (Tokyo) 23: 872-885, 1975.

10. Nohara T, Kumamoto F, Miyahara K and Kawasaki T: Steroid saponins of aerial parts of Paris tetraphylla A. Gray and of underground parts of Trillium tschonoskii Maxim. Chem Pharm Bull (Tokyo) 23: 1158-1160, 1975.

11. Zhao W, Gao W, Wei J, Wang Y, Huang L and Xiao PG: Steroid Saponins and other constituents from the rhizome of Trillium tschonoskii Maxim and their cytotoxic activity. Latin Am J Pharmacy 30: 1702-1708, 2011.

12. Huang W and Zou K: Cytotoxicity of the saponin TTB2 on Ewing sarcoma cells. Exp Ther Med 10: 625-628, 2015.

13. Kohler BA, Sherman RL, Howlader N, Jemal A, Ryerson AB, Henry KA, Boscoe FP, Cronin KA, Lake A, Noone AM, et al: Annual report to the nation on the status of cancer, 1975-2011, featuring incidence of breast cancer subtypes by race/ethnicity, poverty, and state. J Natl Cancer Inst 107: djv048, 2015.

14. Turke AB, Zejnullahu K, Wu YL, Song Y, Dias-Santagata D, Lifshits E, Toschi L, Rogers A, Mok T, Sequist L, et al: Preexistence and clonal selection of MET amplification in EGFR mutant NSCLC. Cancer Cell 17: 77-88, 2010.

15. Su KY, Chen HY, Li KC, Kuo ML, Yang JC, Chan WK, Ho BC Chang GC, Shih JY, Yu SL and Yang PC: Pretreatment epidermal growth factor receptor (EGFK) T790M mutation predicts shorter EGFR tyrosine Kinase inhibitor response duration in patients with non-small-cell lung cancer. J Clin Oncol 30: 433-440, 2012.

16. Güclü-Ustündağ O and Mazza G: Saponins: Properties, applications and processing. Crit Rev Food Sci Nutr 47: 231-258, 2007.

17. Yang SL, Liu XK, Wu H, Wang HB and Qing C: Steroidal saponins and cytoxicity of the wild edible vegetable-Smilacina atropurpurea. Steroids 74: 7-12, 2009.

18. Nordin N, Majid NA, Mohan S, Dehghan F, Karimian H, Rahman MA, Ali HM and Hashim NM: Cleistopholine isolated from Enicosanthellum pulchrum exhibits apoptogenic properties in human ovarian cancer cells. Phytomedicine 23: 406-416, 2016.

19. Chen CX, Zhou J, Zhang YT and Zhao Y: Steroid saponins of aerial parts of paris polyphylla var. Yunnanensis. Acta Bot Yunnan 12: 323-329, 1990.

20. Matsuda H, Pongpiriyadacha Y, Morikawa T, Kishi A, Kataoka S and Yoshikawa M: Protective effects of steroid saponins from Paris polyphylla var. yunnanensis on ethanol- or indomethacin-induced gastric mucosal lesions in rats: Structural requirement for activity and mode of action. Bioorg Med Chem Lett 13: 1101-1106, 2003.

21. Kougan GB, Miyamoto T, Tanaka C, Paululat T, Mirjolet JF, Duchamp O, Sondengam BL and Lacaille-Dubois MA: Steroidal saponins from two species of Dracaena. J Nat Prod 73: 1266-1270, 2010.

22. Huang Y, Cui LJ, Wang Q and Ye WC: Separation and identification of active constituents of Paris vietnamensis. Yao Xue Xue Bao 41: 361-364, 2006 (In Chinese).

23. Martínez MC and Freyssinet JM: Deciphering the plasma membrane hallmarks of apoptotic cells: Phosphatidylserine transverse redistribution and calcium entry. BMC Cell Biol 2: 20, 2001.

24. Demchenko AP: The change of cellular membranes on apoptosis: Fluorescence detection. Exp Oncol 34: 263-268, 2012.

25. Galluzzi L, Kepp O and Kroemer G: Mitochondria: Master regulators of danger signaling. Nat Rev Mol Cell Biol 13: 780-788, 2012.

26. Galluzzi L, Kepp O, Trojel-Hansen C and Kroemer G: Mitochondria control of cellular life, stress, and death. Circ Res 111: 1198-1207, 2012.

27. Zamzami N, Larochette N and Kroemer G: Mitochondrial permeability transition in apoptosis and necrosis. Cell Death Differ 12 (Suppl 2): S1478-S1480, 2005.

28. Brentnall M, Rodriguez-Menocal L, De Guevara RL, Cepero E and Boise LH: Caspase-9, caspase-3 and caspase-7 have distinct roles during intrinsic apoptosis. BMC Cell Biol 14: 32, 2013.

29. Morales-Cano D, Calviño E, Rubio V, Herráez A, Sancho P, Tejedor MC and Diez JC: Apoptosis induced by paclitaxel via Bcl-2, Bax and caspases 3 and 9 activation in NB4 human leukaemia cells is not modulated by ERK inhibition. Exp Toxicol Pathol 65: 1101-1108, 2013.

30. Hardwick JM and Soane L: Multiple functions of BCL-2 family proteins. Cold Spring Harb Perspect Biol 5: pii: a008722, 2013. 